\title{
Property Rights and Natural Resource Conservation. A Bio-Economic Model with Numerical Illustrations from the Serengeti-Mara Ecosystem
}

\author{
ANNE BORGE JOHANNESEN and ANDERS SKONHOFT* \\ Norwegian University of Science and Technology, Department of Economics, NO-7491 Trondheim, \\ Norway; *Author for correspondence (e-mail: anders.skonhoft@ svt.ntnu.no)
}

Accepted 5 October 2003

\begin{abstract}
This study develops a model for wildlife migrating seasonally between a conservation area and a neighbouring area. When being outside the conservation area, harvesting takes place by a group of small-scale farmers. The local people have two motives for harvesting; to get rid of "problem" animals as roaming wildlife destroys crops and agricultural products, and hunting for meat and trophies. Depending on the specification of the property rights, the harvesting is legal or illegal. It is demonstrated that it is far from clear which of the two property rights regimes that gives the highest wildlife abundance. Hence, contrary to what is argued for in the literature, handing the property rights over to the local people means not automatically more wildlife and a more "sustainable" resource utilization. The reason lies in the nuisance motive for harvesting. The exploitation under the two different property rights regimes are illustrated by numerical calculations with data that fits reasonable well with the exploitation of the wildebeest population in the Serengeti-Mara ecosystem.
\end{abstract}

Key words: bio-economics, property rights, Serengeti, wildlife

JEL classifications: Q21, Q28

\section{Introduction}

For a long time it has been recognised that institutions play an important role in natural resource management, and that the specification and function of property rights to a large extent determine whether resources can be utilized in a sustainable way. These dimensions will be at the focus in the present study when analysing the management and exploitation of wildlife in a sub-Saharan Africa context with example from the Serengeti-Mara ecosystem. When considering natural resources in the form of wildlife in this region, as in other regions in the sub-Saharan Africa, central issues are the behaviour of the local people living close to the wildlife, and the interaction between the local people, the wildlife and the agency managing and having the legal property rights of the wildlife. Often this interaction represents conflicting interests; both the legal owner of the wildlife (usually the State, or large 
private landowners) and the rural people claim their rights to reap the benefits of the huge amount of wildlife resources. In addition, the costs of having abundant wildlife populations differ between them. These conflicts, rooted in the prevailing property structure and its functioning, have serious implications for the resource exploitation and, thus, on the management of the wildlife in general (Marks 1984; Kiss 1990; Swanson and Barbier 1992; Naughton-Treves and Sanderson 1995; Sinclair and Arcese 1995; Skonhoft and Solstad 1998; Bulte and van Kooten 1999).

The common perception in the literature is that local communities will support wildlife conservation and reduce the wildlife offtake if they are ensured a sufficient share of the benefits from wildlife (see Kiss 1990; Swanson and Barbier 1992; Mangel et al. 1996). Under what conditions a community based management system results in a higher wildlife abundance and more conservation than the polar scheme where the local people have no legal rights to wildlife exploitation, is analysed in the present paper. The starting point is that we have a protected area, a national park or a conservation area of fixed size, with no harvesting of the wildlife. The protected area is the basic living area of the species, but the animals roam freely in and out of the park. When being outside, the game destroys the crops of the farmers living in the vicinity of the park and hence, the wildlife represents a nuisance for the local people. The park agency has the property rights of the wildlife within as well as outside the protected area, but illegal harvesting takes place outside as the property rights is not effectively protected here. This is the first regime where the local people have no property rights. ${ }^{1}$ In the next step, the property rights are handed over to the local people and hence, the exploitation of the wildlife outside the protected area takes place in a legal manner. ${ }^{2}$ The different degree of wildlife utilization is compared under these two regimes, and contrary to what is argued for in the literature the first property rights scheme may result in the highest wildlife abundance. Analysing the driving forces behind such an outcome is the main contribution of this paper.

The hunting activity and the utilization of the wildlife under these two regimes are exemplified by the migration of wildebeest in the Serengeti-Mara ecosystem. The migration pattern here, which is seasonal and related to rainfall and food supply, is also used as a motivation for the ecological part of the model. Parts of the year the migratory wildebeest population is staying within the huge Serengeti national park and it is assumed that no human extraction takes place here. ${ }^{3}$ However, when being outside there is hunting. The conceptual framework for analysing the exploitation of a terrestrial animal population when there is migration, and hunting is a seasonal activity, is another contribution of the paper.

To simplify the following analysis we consider only two areas; the protected area and the whole boundary region collapsed into one boundary area. The protected area is the basic living area of the wildlife and is owned and managed by the State. No human extraction is allowed here, and hence, non-consumptive benefit (tourism, existence value, etc.) is the only benefit of this area. However, the 
park manager play no role in the subsequent model as the management of this area is supposed to have no stock effects (no harvesting and no culling, but see Wright 1999). The small-scale farmers are living in the boundary area, where the wildlife roams during the migration season. They are involved in two production activities; agricultural crop production and wildlife hunting (see e.g., Barrett and Arcese 1998). First, we study today's situation where the local people have no property rights, and hence, they hunt illegal. This is in accordance with the "open-access" model of Smith (1975). Under this scenario we disregard any enforcement use and consequently, the park manager is passively benefiting from non-consumptive utilization of wildlife in the protected area. In a next step, we study what happens when the property rights over the wildlife are given to the local people.

We start by formulating the ecological model and the migration pattern in section 2. In section 3 the benefit function of the local people is presented, and in section 4 it is studied how this translates into harvesting when they have no property rights. In this section, as later, it will for simplicity be assumed that only the current benefit, or current utility, is steering the harvesting activity. In section 5 the model is analysed when the local people have the property rights over the wildlife. In section 6 the two different property rights regimes are illustrated by numerical calculations with data that fits reasonable well to the exploitation of the wildebeest population in the Serengeti-Mara ecosystem.

\section{The Ecology}

As already noted, we consider a wildlife population (e.g., wildebeest) migrating over the year in a well defined way, and where harvesting only takes place when the wildlife are outside their core area, i.e., the conservation area or the national park. Because the seasonal migration is related to rainfall and food supply, there is no density-dependent factors influencing the wildlife flow. For simplicity it is assumed that the whole wildlife population is leaving the core area, and we separate sharply between the periods of the year when the wildlife is roaming outside and when the animals are staying inside of the protected area. These two periods are synonymous with the "fishery season" and "between season" in Homans and Wilen (1997). ${ }^{4}$ We start by formulating the hunting season dynamics while the between season dynamics and the steady state follow next.

\subsection{MIGRATION AND HARVESTING}

As mentioned above, harvesting takes place only during the period of migration, i.e., when the wildlife is roaming outside the conservation area. Further, we do not separate between different hunting strategies within the harvesting period. This is in line with Homans and Wilen's fishery model (1997), where harvesting effort is utilized at a constant rate throughout the period when harvesting takes place. For a critical assessment of this assumption, see Getz and Haight (1989). The wildlife 
harvesting function is specified as a Schaefer function giving the harvest at time $t$ as

$$
h(t)=q a X(t)
$$

where $X(t)$ is the wildlife stock (measured as biomass), while $a \geq 0$ is the harvesting effort considered variable between the seasons, but fixed within a season of migration. $q$ is a parameter, the so-called catchability coefficient.

When being within the conservation area the wildlife grows in a densitydependent fashion (see below), and when being outside natural mortality is ignored. ${ }^{5}$ Outside the conservation area the stock therefore shrinks according to $d X(t) / d t=-q a X(t)$. The stock level outside the conservation area at time $t$ is accordingly

$$
X(t)=X_{0} e^{-q a t}
$$

where $X_{0}$ is the stock level when the species starts roaming outside the protected area.

The length of the migration period, i.e., the time when being outside the conservation area, is fixed as $T$. Hence, the stock level when the wildlife is returning back to the park is

$$
X_{T}=X_{0} e^{-q a T}=X_{0} s
$$

where $a T$ is the total hunting effort in the migration period, and $0<s=e^{-q a T} \leq 1$ is accordingly the survival rate of the species when being outside the conservation area. Under these assumptions, total amount of wildlife harvested is

$$
H=X_{0}-X_{T}=X_{0}(1-s) .
$$

\subsection{NATURAL GROWTH AND ECOLOGICAL EQUILIBRIUM}

So far we have studied a single period migration, where the stock size $X_{0}$ at the beginning of the period of migration is predetermined. However, as the number of animals harvested depends on the initial stock, the harvest changes when $X_{0}$ changes. The factors affecting the initial stock size are found by analysing the dynamics between the seasons of migration. We assume that the conservation area is the basic living area where calving takes place, meaning that the stock size returning back determines the natural growth. When $X_{T, t}$ is the stock returning back to the conservation area at time $t$, the density-dependent growth is accordingly determined as $F\left(X_{T, t}\right)$. We represent natural growth by a logistic function with $K$ as the carrying capacity and $r$ as the maximum specific growth rate, where both parameters are treated as fixed. ${ }^{6}$ Hence, we ignore any possible feedback from consumption of agricultural crops on the natural growth. This seems reasonable when assuming that the fraction of fodder eaten from agricultural crops is low or, 
in shortage of crops, the consumption may switch to wild dry fodder. See also section 3 .

If $X_{0, t+1}$ is the stock level at the beginning of the next period of migration, then the dynamics between the migration seasons is given by

$$
X_{0, t+1}=X_{T, t}+F\left(X_{T, t}\right)=X_{T, t}+r X_{T, t}\left(1-X_{T, t} / K\right) .
$$

Equation (5) together with the balance equation (4) written as $H_{t+1}=X_{0, t+1}-$ $X_{T, t+1}$, yields $H_{t+1}+X_{T, t+1}=X_{T, t}+F\left(X_{T, t}\right)$. Ecological equilibrium is defined by a constant wildlife stock returning back to the park area, $X_{T, t}=X_{T, t+1}=$ $X_{T}{ }^{7}$ In steady-state, natural growth, taking place within the conservation area, is therefore equal to harvesting, taking place in the surrounding area, $F\left(X_{T}\right)=H$. When substituting for the logistic growth function and equation (3) and using (4), we obtain $r X_{0} s\left(1-X_{0} s / K\right)=X_{0}(1-s)$. Consequently, the ecological equilibrium is given by $X_{0}=0$ and

$$
X_{0}=(K / r s)(1+r-1 / s)
$$

with $(1+r-1 / s)>0$. From this equation it follows that the equilibrium stock returning back to the conservation area is equal to $X_{T}=(K / r)(1+r-1 / s)$. Because more harvesting effort reduces the survival rate $s$, more effort also clearly reduces the stock size, $\partial X_{T} / \partial a<0$. From the equilibrium condition $X_{0}=X_{T}+$ $F\left(X_{T}\right)$, we also have $\partial X_{0} / \partial a<0$ as long as $-1<F^{\prime}$. When evaluating $F^{\prime}$ at the equilibrium, or differentiating equation (6) directly, this condition also writes $[2 / s-(1+r)]>0$. In what follows, this is assumed to hold.

\section{Agricultural Production, Crop Damage, and Harvesting}

Above we established the ecological steady-state for a fixed amount of hunting effort. However, the hunting activity is determined by economic considerations and now these motives are outlined. Throughout we will think of the local people as a homogeneous group of small-scale farmers living in the boundary area of the park. ${ }^{8}$ They are involved in two different production activities; agricultural production and wildlife hunting. In the model, as in reality, there are two basic motives behind hunting. In addition to the already mentioned nuisance motive where hunting takes place to get rid of "problem" animals destroying crops and agricultural products, there is also hunting for meat or, occasionally, for trophies (Marks 1984; Barrett and Arcese 1998). Because of small funds and large areas, the harvesting, when being illegal, takes place in an environment lacking any enforcement use.

We first look at the nuisance motive working through the agricultural yield function. The maximum agricultural yield, i.e., the yield without damage, depends on the amount of agricultural land, pesticides and fertiliser use, rainfall, etc., and effort use. Keeping all factors fixed except of effort, the yield function reads

$$
A=A(N)
$$


where $N$ is the total (cumulative) labour input in agricultural production over the year (seeding, harvesting and maintaining the crop). $A$ is an increasing function of $N$ with $A(0)=0$, but at a decreasing rate, so that $A^{\prime}(N)>0$ and $A^{\prime \prime}(N) \leq 0$ hold.

More wildlife means more nuisance, and following Zivin et al. (2000) we assume that the damage is proportional to the amount of wildlife. It is assumed that wildlife consumes a fraction $\beta$ of its body weight in forage dry matter per day. As mentioned above, while grazing in the outer area, the wildlife consumes both agricultural crops and other dry matter. In the following, the fraction eaten from crops is denoted $\gamma$. The nuisance stream at time $t$ is therefore $\gamma \beta X(t)$ with $0<\beta<1$ and $0 \leq \gamma \leq 1$ as fixed constants. ${ }^{9}$ Consequently, the cumulative damage of the wildlife roaming outside the conservation area is

$$
D=\gamma \beta X_{0}(1-s) / q a
$$

when using equation (2) and integrating. If $P_{A}$ is the crop price, assumed to be fixed, and leaving out fertiliser and pesticides costs, etc., the net crop benefit is

$$
B=P_{A}[A(N)-D],
$$

with $D$ defined in the interval $[0, A(N)]$ as the damage can never exceed the yield. The nuisance motive for harvesting is therefore working through $D$. More harvesting reduces the damage for a given stock size as the total amount of harvested animals increases.

In addition to the nuisance motive, we have the direct benefit of hunting in the form of meat (and trophies). The hunting benefit is given as

$$
V=P_{H} H=P_{H} X_{0}(1-s)
$$

where $P_{H}$ is the marginal valuation, or price, of the offtake, also assumed to be fixed.

There will be a constraint on effort used in hunting and crop growing. As $a$ is hunting effort per unit of time and $T$ is the length of the migration and hunting season, this resource constraint reads

$$
L \geq a T+N .
$$

$L$ is the total available time per year, which also can be interpreted as the total human population living in the vicinity of the conservation area. Throughout the analysis $L$ is fixed, meaning that we are ignoring any, if possible, Malthusian mechanism. Moreover, all the time the constraint is assumed to be binding, and hence, there is always a positive opportunity cost of labour use.

When using the resource constraint, we obtain the total current benefit of the local people as

$$
U=P_{H} X_{o}(1-s)+P_{A}\left[A(L-a T)-\gamma \beta X_{0}(1-s) / q a\right] .
$$

In the next section, we determine the optimal harvesting effort and wildlife population when the local people have no property rights to the wildlife roaming in the 
outer area. In section 5, we study the polar case when they are given full property rights.

\section{No Property Rights of the Local People}

Assuming that the local people have no property rights corresponds, as already mentioned, to the stylised facts situation in sub-Saharan Africa today, and may be understood as a regime where the local people face a continuous risk of being effectively excluded from hunting in the future, e.g., due to more extensive use of law-enforcement effort. They are therefore not able to control the wildlife stock, and have few, if any, incentives to base their harvesting on long-term considerations. Technically, the absence of long-term considerations means that they do not take the stock of wildlife into account when deciding their effort use, and the number of animals entering the boundary area is consequently treated as an exogenous variable. As already mentioned, this corresponds to what Smith (1975) calls an "open-access" solution. See also Skonhoft and Solstad (1998).

Maximizing the benefit function (12) with respect to the control $a$, when keeping $X_{0}$ exogeneous, yields the first order condition

$$
P_{A} A^{\prime}(N) T-P_{A} \gamma \beta X_{0} C / a=P_{H} X_{0} q T s
$$

when we have an interior solution so that effort is allocated to both production activities. $C$ collects terms, and reads $C=(1 / q a)[1-(1+q a T) s]>0 .{ }^{10}$ The optimal hunting effort is therefore determined by the equality between the marginal benefit in agricultural production, corrected for damage of the roaming wildlife, and the marginal hunting benefit. This economic equilibrium is illustrated in Figure 1 where the marginal net benefit from agricultural production MBA is measured along the left hand vertical axis, while the marginal hunting benefit $\mathrm{MBH}$ is measured along the right hand axis. The second term on the left hand side of condition (13) reflects the nuisance motive caused by crop damage. Crop damage reduces the marginal profitability in agricultural production, and consequently, the local people channel more effort to hunting compared to a situation when crop damage is absent and $\gamma=0$. This is illustrated by the downward shift in the marginal net agricultural benefit curve in the figure.

The economic equilibrium condition (13) together with the ecological equilibrium condition (6) defines the equilibrium values of hunting effort $a^{\infty}$ and the initial stock size $X_{0}^{\infty}$ (superscript " $\infty$ " denotes no property rights of the local people). In a next step, the equilibrium wildlife population returning back to the park area at the end of the season $X_{T}^{\infty}$ is found by using equation (3). When taking the total differential of these equations, the economic and ecological forces at work can be demonstrated (for details, see Appendix 1). The results are reported in Table I. As already indicated, a higher nuisance effect reduces the marginal productivity of agricultural production and, hence, the local people increase their harvesting effort, $\partial a^{\infty} / \partial \gamma>0$. Consequently, the initial stock $X_{0}^{\infty}$ decreases, and 


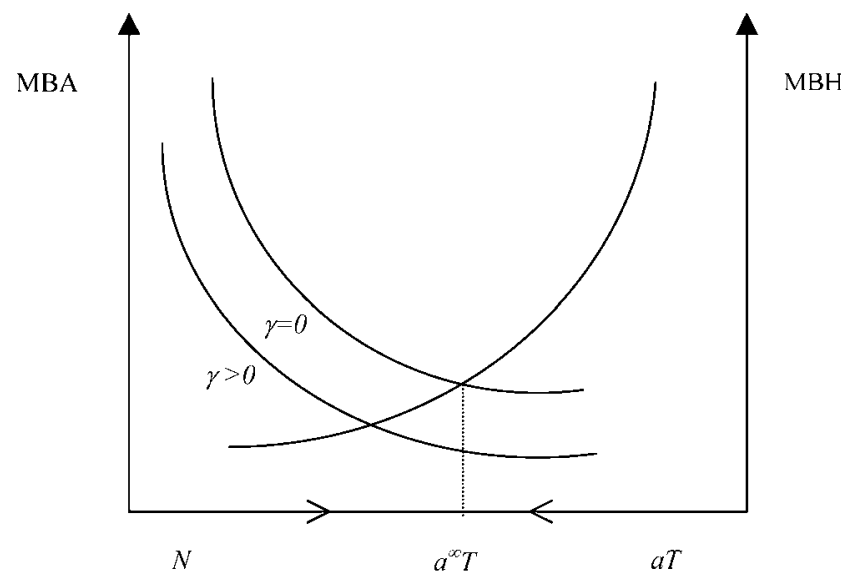

Figure 1. Economic equilibrium. No property rights regime.

Table I. Comparative static results

\begin{tabular}{|c|c|c|c|c|}
\hline \multirow[t]{2}{*}{ Parameter } & \multicolumn{2}{|c|}{ No property rights } & \multicolumn{2}{|c|}{ Property rights } \\
\hline & $a^{\infty}$ & $X_{0}^{\infty}$ & $a^{*}$ & $X_{0}^{*}$ \\
\hline$\gamma$ & + & - & + & - \\
\hline$P_{A}$ & - & + & $-/+$ & $+/-$ \\
\hline$P_{H}$ & + & - & $+/-$ & $-1+$ \\
\hline$T$ & $?$ & $?$ & $?$ & $?$ \\
\hline$L$ & + & - & + & - \\
\hline$Q$ & $?$ & $?$ & $?$ & $?$ \\
\hline$R$ & + & + & $?$ & $?$ \\
\hline$K$ & + & + & $?$ & $?$ \\
\hline
\end{tabular}

Note: When "+/-"; a reduction in $a^{*}(-)$ is accompanied by a higher $X_{0}^{*}(+)$, and vice versa. When "?"; ambiguous sign.

this will also be so for $X_{T}^{\infty}$. A higher price of game meat will also motivate for more hunting effort, $\partial a^{\infty} / \partial P_{H}>0$, and hence, $X_{T}^{\infty}$ as well as $X_{0}^{\infty}$ decrease. A higher crop price causes the local people to divert more effort towards agriculture and the stock will increase, $\partial X_{0}^{\infty} / \partial P_{A}>0$. This result is in line with the analysis in Skonhoft and Solstad (1998), who find that better economic conditions in the agricultural sector always works in the direction of more wildlife conservation when the land use, as here, is fixed.

The effect of a higher $T$ is ambiguous. First, a longer migration period reduces the productivity of hunting as an instrument of damage control. This causes the local people to channel more effort towards agricultural production. Second, the marginal product of hunting for meat increases with the period of migration, leading the local people to increase their hunting effort. Consequently, if the costs of living with wildlife exceed the benefit, then more effort is directed to agricul- 
ture. However, the effect on total hunting effort $(a T)$ and wildlife conservation is unclear. For other results, see Table I.

\section{Property Rights to the Local People}

Above the harvesting activity and stock sizes were found when the local people had no property rights and hence, the harvesting activity was not based on long-term considerations. Now we proceed to study what happens in the polar case when the property rights are handed over to the local people and they do no longer harvest illegally, and hence, we have a community based management scheme. When not facing any risk of being effectively excluded from hunting in the future, they will invest in wildlife and therefore take the wildlife abundance into account when allocating effort among the two production activities. Technically, the wildlife stock $X_{0}$ is now an endogenous variable, and the problem is therefore to maximize (12) with respect to $a$, subject to the ecological constraint (6). ${ }^{11}$

The first order condition for this problem is

$$
\begin{aligned}
& P_{A} A^{\prime}(N) T-P_{A} \gamma \beta X_{0} C / a \\
& \quad-\left[P_{A} \gamma \beta-P_{H} q a\right] q T(1-s) K[2 / s-(1+r)] / \text { qars }=P_{H} X_{0} q T s
\end{aligned}
$$

when still assuming an interior solution. This equation together with equation (6) determines the equilibrium effort $a^{*}$ and equilibrium stock size $X_{0}^{*}$, while $X_{T}^{*}$ again follows from equation (3) (superscript "**" denotes the property rights case). The difference compared to the economic equilibrium condition (13) in the case of no local property rights, is the third term on the left hand side. $[2 / s-(1+r)]$ is here positive because $\partial X_{0} / \partial a<0$ holds (see section 2). The new term, depending on the sign of $\left[P_{A} \gamma \beta-P_{H} q a\right]$, can therefore be either positive or negative, and hence, $a^{*}$ can be below as well as above that of $a^{\infty}$. Consequently, $X_{0}^{*}$ can also be above or below that of $X_{0}^{\infty}$.

The general conclusion following the model is therefore that it is unclear whether handing the property rights over to the local people will result in a higher wildlife abundance and a more "sustainable" resource utilization. On the one hand, having the property rights and taking the size of the wildlife into account when determining hunting effort, work in the direction of a higher stock size. However, at the same time, crop damage related to the size of the wildlife will also be taken into account, and this works in the other direction. The actual outcome depends critically on whether the marginal nuisance of the wildlife stock dominates the marginal harvesting benefit; that is, the sign of the term $\left[P_{A} \gamma \beta-P_{H} q a\right]$ above. If $P_{H} q a>P_{A} \gamma \beta$ holds we therefore obtain the standard result from the literature saying that the presence of property rights means less harvesting effort and more wildlife conservation compared to the no property rights case; that is, $a^{*}<a^{\infty}$ and $X_{0}^{*}>X_{0}^{\infty}$. On the other hand, when the marginal nuisance dominates the marginal harvesting productivity, the nuisance case, we obtain $a^{*}>a^{\infty}$. Hence, taking the nuisance into account yields less wildlife than not doing so, $X_{0}^{*}<X_{0}^{\infty}$. 
The comparative static results are now found by taking the total differential of equations (14) and (6) (for details, see again Appendix 1). More nuisance increases the agricultural damage and, hence, reduces the marginal benefit from crop production. This direct effect is the same as in the no property rights case, and increases the equilibrium hunting effort. In addition there is now an indirect effect working through the stock size at the beginning of the next hunting season, which reinforces the direct effect. $\partial a^{*} / \partial \gamma$ is therefore stronger when there are local property rights. The direct effect of a higher game meat price is more benefit from hunting. As for the no property rights regime, this motivates for increased hunting and stock depletion, which is the same result as in the standard harvesting model (see e.g., Clark 1990). Now, however, this effect is weakened because a higher offtake reduces the crop damage and hence, motivates for more effort allocated to crop production because the crop damage is taken into account. Thus, the indirect effect is of the opposite and the sign of $\partial a^{*} / \partial P_{H}$ is ambiguous. In the same way, the effect of a higher agricultural price is ambiguous. These results contrast the no property case, but are in line with results from harvesting models with competing uses among different assets (see e.g., Swallow 1990). Other results are again given in Table I, and as seen, the outcomes are to a large extent ambiguous.

\section{Numerical Illustrations}

The theoretical reasoning will now be illustrated by data that fits reasonable well with the exploitation of the wildebeest population in the Serengeti-Mara ecosystem. This ecosystem covers an area of some $25,000 \mathrm{~km}^{2}$ on the border of Tanzania and Kenya (Sinclair 1995). The Serengeti National Park is a part of it, and is wide known for the migration of its large herbivore populations of which the wildebeest has been most in the focus. Each year about a million wildebeest migrate across the Serengeti-Mara ecosystem (Murray 1995). The overall migratory pattern is supposed to be related to food supply, which in turn is connected to rainfall. The Serengeti ecosystem can be divided into two main regions; the southern short grasslands with low annual rainfall and the wooded northern grassland with higher rainfall (Fryxell 1995). The migratory wildebeest use the short grasslands in the south during the wet season and the tall grassland in the north during the dry season (Sinclair 1984, 1995; Fryxell 1995).

The migratory herds know no boundaries, and make extensive use not only of the gazetted land, but also the open areas in the districts outside the borders of Serengeti National Park (cf. Figure 2). During the migration they spread beyond the park into the western frontier and enter land settled by humans. This side of Serengeti National Park is densely populated, and the population is increasing (Barrett and Arcese 1998). As a consequence, there are threats to the species diversity and the ecosystem because the landscape is modificated and habitat land is converted into agricultural use (Sinclair and Arcese 1995). The detrimental effects of the human-wildlife interaction are, however, not only one-way. The local people and 


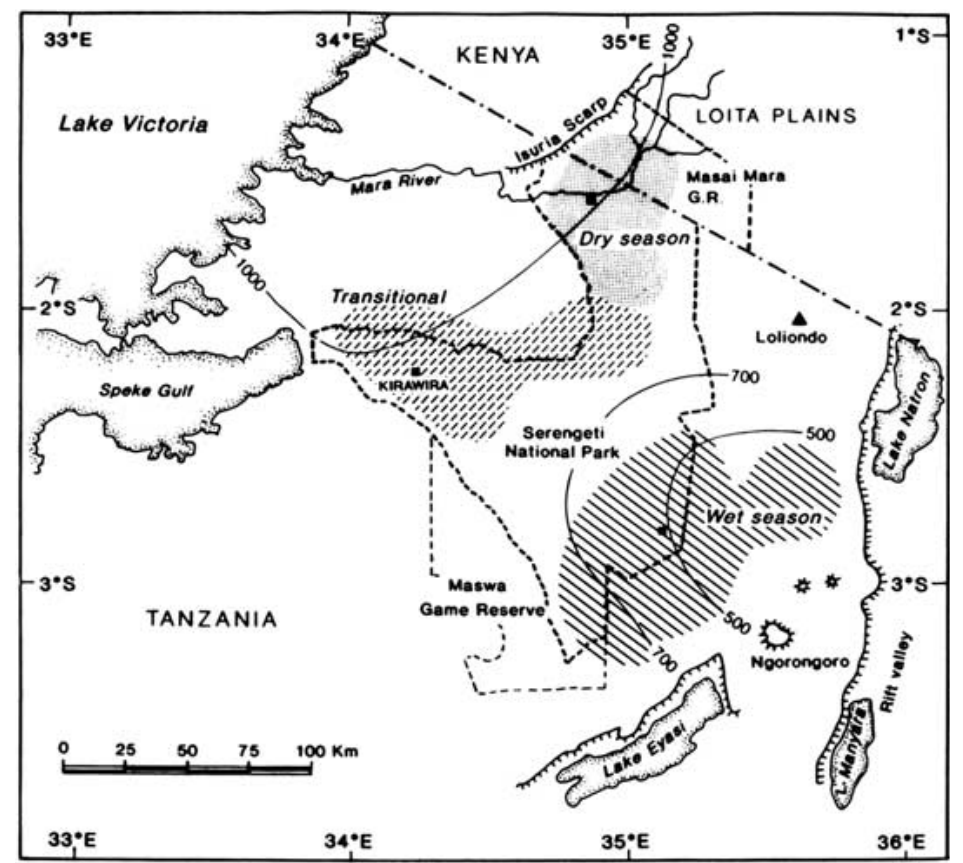

Figure 2. The seasonal ranges occupied by migratory wildebeest in the Serengeti-Mara ecosystem (adopted from Murray 1995).

the local communities also bear costs from the high wildlife abundance as the large herds of migrating herbivores induce crop damage (Emerton and Mfunda 1999). Villagers protect their crops and compensate themselves by hunting; in addition they also hunt for meat (Arcese et al. 1995). Hunting in this region is basically illegal. ${ }^{12}$ Therefore, living with wildlife is twofold; it represents a cost to the small-scale farmers due to crop damage while it represents a benefit due to illegal harvesting.

The ecological model, using the Serengeti-Mara ecosystem as an illustration, is specified for the numerical analysis at the scale of one $\mathrm{km}^{2}$ and one year. The same scale is also used for the agricultural benefit as well as the hunting benefit. The closer definition of the protected area and the outer area is found in Appendix 2. The baseline values for prices and costs together with ecological data and data for crop production used in the simulations are also presented here. As demonstrated above, the conservation effect of giving the local people property rights depends critically on the costs and benefits of living with wildlife. Because of the unclear nuisance effects, the damage coefficient $\gamma$ will be varied throughout the simulations where a low value of $\gamma$, as mentioned, may be interpreted as more extensive use of fencing or other measures taken to protect crop production from the roaming wildlife. In addition, because of the unclear price effect under the property rights scenario, we will also vary the crop price $P_{A}$. The conservation effect of shifting 


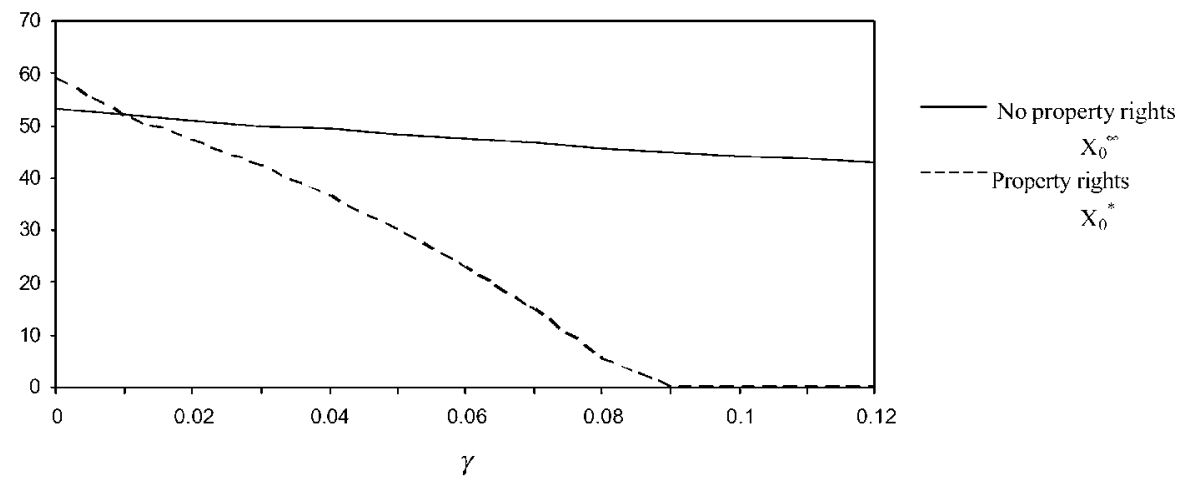

Figure 3. The conservation-damage schedules. Number of animals per square km.

the hunting price $P_{H}$ together with changing ecological and productivity conditions will be studied as well.

Figure 3 demonstrates how the wildlife abundance varies with the crop damage coefficient $\gamma$ under both property right schemes. More nuisance means less wildlife, and hence, the conservation-damage schedule slopes down under both scenarios. However, in accordance with the theoretical reasoning, the nuisance effect is quite more substantial under the local property rights regime. The figure also demonstrates that handing the property rights over to the local people gives more wildlife only when the crop damage is quite low. Hence, only when $\gamma<0.01$ and less than $1 \%$ of the forage is eaten from the crop, local property rights results in higher wildlife abundance. Within this range the marginal benefit of living with wildlife exceeds the marginal cost, i.e., the term $\left[P_{A} \gamma \beta-P_{H} q a\right]$ from section five is negative. The figure also demonstrates that the nuisance effect is so strong that the presence of local property rights means a total depletion of the wildlife when more than $9 \%$ of the forage is eaten from the crop. Hence, according to the model and the imposed parameter values where the baseline value of the damage coefficient is $12 \%, \gamma=0.12$ (see Appendix 2), the presence of local property rights would have meant an extinction of the wildlife.

Under the prevailing economic conditions, handing the property rights over to the local community is therefore not likely to promote wildebeest conservation in Serengeti. A better conservation strategy is probably to impose tighter damage control and, hence, reduce the cost of living with wildlife. The figure demonstrates, for instance, that a total eradication of crop damage from today's level (i.e., $\gamma$ reduces from 0.12 to 0.00 ), increases wildlife abundance by somewhat above $20 \%$ within the present property rights regime. This effect may further be strengthened if combined with, say, increased productivity and profitability in agricultural production as a higher crop price means more wildlife and conservation. This will be so within both regimes, and both conservation-damage schedules in Figure 3 shift up when $P_{A}$ increases. However, contrary to what is expected from the theoretical reasoning, the effect is stronger under the property rights regime, and, for instance, 
we find that the same degree of conservation is met for $\gamma=0.03$ when $P_{A}$ is doubled from today's level. Shifting up the crop productivity works in the same manner while a higher game meat price $P_{H}$ motivates for more hunting within both property rights schemes, and both conservation-damage schedules in Figure 3 shift down accordingly. A positive shift in the catchability coefficient $q$ due to, say, improved hunting technology, also means reduced wildlife abundance within both property rights schemes, and the same degree of conservation is met for a higher value of the damage coefficient. We have also studied the effects of shifting the migration period $T$, interpreted as taken place as a result of, say, drought. The conservation-damage schedules, however, are only modestly influenced.

\section{Discussion and Concluding Remarks}

There is a growing recognition that a viable and sustainable wildlife utilization in the future depends on the support of the local communities living close to the wildlife, and during the last years community based wildlife management projects have increasingly become one of the means for safeguarding wildlife in sub-Saharan Africa (Kiss 1990; Swanson and Barbier 1992). The basic idea behind these schemes is to engender the co-operation of local communities in wildlife conservation and wildlife management by ensuring that parts of the benefits from wildlife utilization go to the local communities. There are several ways in which benefit sharing can take place; through revenue sharing from tourism, safari hunting, or establishing user rights through hunting quotas (see Barrett and Arcese (1998) and Skonhoft 1998 for some analyses), or through local job creation in tourism, wildlife and park services. The experiences from two prototypes of community based projects are summarised by Kiss (1990), namely Windfall and Campfire (both in Zimbabwe).

What has been analysed in this paper is a more far-reaching community based management system as the local people have been given the full property rights of the wildlife; that is, they control and obtain the whole benefit stream from the wildlife when it is outside the protected area. This management scheme has been compared to the polar one of having no property rights. Under the scenario of no property rights, the local people have no incentive to take into account that their hunting today influences the wildlife stock and hence, reduces the potential for hunting next year. Technically, the stock size is then treated as an exogenous variable when allocating hunting effort, and is in line with the "open-access" solution of Smith (1975). In the next step, when assuming that the property rights are handed over to the local people, they have incentives to invest in the wildlife stock, and take the stock size into account when hunting. Smith (1975) specifies this scenario within an inter-temporal framework where the present-value benefit is maximized. The present exposition where the local people consider the wildlife stock as an endogenous variable under ecological equilibrium coincides with the steady-state of the Smith model when the discount rate is zero (see also Munro and Scott 1985). 
The main point of the analysis is to find under what conditions community based management and property rights of the local people might result in a higher wildlife abundance compared to the no property rights scenario. It is shown that the actual outcome depends critically on the difference between the benefit and cost of living with wildlife; that is, the marginal harvesting value versus the marginal crop damage. Accordingly, only when the nuisance from the roaming wildlife is small and the marginal benefit exceeds the cost, we find that community based management increases the wildlife stock compared to the scenario of no property rights. The main message from the theoretical analysis is therefore that relying on local property rights alone as a tool in wildlife conservation may not work. This conclusion contrasts Kiss (1990) and Swanson and Barbier (1992) who argue that local property rights generally will promote wildlife conservation.

The theoretical model is illustrated by data that represents the Serengeti-Mara ecosystem in a stylised manner. For the baseline parameter values the nuisance from the wildlife dominates the benefit, and hence, local property rights may give incentives to deplete the roaming stock of wildebeest. A better conservation strategy than handling the property rights over to the local people is probably to protect crop production by supporting fencing or take other types of control measures to reduce the damage caused by the roaming wildlife. The numerical simulations also demonstrate that an increased crop price or higher crop productivity through, say, improved fertiliser and pesticides use, may lead the local people to channel more effort towards agricultural production. Hence, such measures will also work in the direction of more wildlife conservation. This conclusion is in line with Barrett and Arcese (1998) who find that to succeed promoting wildebeest conservation in Serengeti, wildlife management schemes must attempt to increase local people's benefit from alternative activities.

The focus of the present analysis has been property rights and wildlife conservation. The basic idea behind giving the local people full property rights over the wildlife is, however, to promote wildlife conservation together with economic development and increased welfare (see e.g., Kiss 1990). Ceteris paribus, the presence of property rights increases the welfare of the local people compared to the scenario of no property rights as both effort and wildlife abundance are adjusted optimally within this regime, while only effort is adjusted within the no property rights regime. When the damage of the roaming wildlife is small so that the benefit of living with wildlife exceeds the cost, we can therefore conclude that the presence of local property rights promotes wildlife conservation as well as local welfare. On the contrary, according to our numerical results, local welfare is promoted at the expense of wildlife conservation when the cost of living with wildlife exceeds the benefit.

Throughout the analysis the local people has been treated as a homogeneous group with no internal conflicting interests. From a conservation point of view, both property rights scenarios have thus been implemented in the most optimistically way. Under both scenarios, it is also assumed that the local people reap benefit 
from wildlife harvesting only; that is, possible income transfers from park activities and tourism is ignored in the analysis. Implementing such transfers will increase the benefit of living with wildlife, which may lead to more wildlife conservation in the local property rights regime. However, a complete analysis of income transfers requires a two-agent model, i.e. the park manager and the local people, and as demonstrated in Skonhoft (1998) such income transfers may impel unintended negative conservation effects.

\section{Acknowledgement}

We would like to thank Jan Tore Solstad and a reviewer for valuable comments and for funding from Norwegian Research Foundation, and The European Commission, through the program BIOECON.

\section{Notes}

1. Economists frequently confuse what is meant with property rights. Daniel Bromley understands property as a benefit stream and a property right as "the capacity to call upon the collective to stand behind one's claim to a benefit stream" (Bromley 1991, p. 15). Possession of inviolable property rights presupposes that the rights are authorised by law and that the law is effectively enforced by the state. Hence, a well-functioning property regime is characterised by, firstly, legally welldefined property rights and, secondly, effectively protected property rights. The existence or non-existence of these two factors defining the functioning of the property structure can be used to classify three different types of regimes. First of all we have the case where there is legally well-defined ownership and perfect state protection (exclusive rights, perfect law enforcement). This is in accordance with the classical Clark (1973) model. Secondly, we have the case where the ownership is legally well defined but not adequately enforced by the government. Under such a scheme, often due to lack of societal recognition of the property rights in place, the management is likely to be affected by conflicting property rights claims. Finally, we have the case where there is no legally defined ownership; that is, the open-access case regime (Gordon 1954). Hence, the second of these regimes is the starting point in the following analysis.

2. These schemes are polar because the local people obviously can obtain other rights than full property rights of the wildlife when being outside the park, say, through a specific harvesting quota, the rights to harvest problem animals, and so forth. Moreover, not analysed here, they can also obtain property rights of the wildlife when being inside the park through tourism benefits (cf. the concluding section).

3. In reality, poaching takes place within as well as outside the borders of Serengeti National Park (see Sinclair and Arcese 1995). However, to simplify the theoretical framework, without altering the qualitative results, we assume that hunting is only taking place in the outer area.

4. There are few, if any, papers analysing time discrete models with migration for terrestrial animal species within a bio-economic concept. Fancy et al. (1994) formulate a time discrete migration model for the porcupine caribou herd. The migration here is also seasonal, but this paper has no economic content.

5. Introducing natural mortality makes the model quite more complicated, but it will not change the qualitative content of the analysis.

6. As in Barrett and Arcese (1998) we use a single species (i.e., wildebeest), non age-specific (biomass) model. This also implies that the hunting is considered as non-selective, an assumption 
consistent with the largely passive nature of the main hunting method in the Serengeti area, namely snaring (see Campbell and Hofer 1995; Holmern et al. 2002).

7. Combining equation (5) and equation (3) written as $X_{T, t+1}=X_{0, t+1} s$ yields $X_{T, t+1}=$ $s\left[X_{T, t}+F\left(X_{T, t}\right)\right]=G\left(X_{T, t}\right)$. It is well known (see e.g., Clark 1990, Ch. 7) that the condition for stability is that $-1<G^{\prime}<1$ holds at the equilibrium. We have $G^{\prime}=s\left(1+F^{\prime}\right)=$ $s\left[1+\left(r-2 r X_{T, t} / K\right)\right]$ which at the equilibrium reads $s[2 / s-(1+r)]$ when inserting for $X_{T}$ (see the main text). Hence, stability demands $1 / s-(1+r)<0$ and $3 / s-(1+r)>0$. The first of these conditions is therefore the same as the condition for obtaining an interior steady-state, while the second condition is fulfilled if $\partial X_{0} / \partial a<0$ holds (see the main text).

8. It is therefore assumed that there are no conflicting interests among them. Hence, prevalence of individual conformity to group norms is assumed to be present. In line with traditional reasoning, it is assumed that the elders are in charge of the group's activities (Marks 1984). This obviously means that the scenario of property rights to the local people in section 5 is implemented in its most optimistically way (cf. the concluding section).

9. We assume that hunting is the only damage control performed by the local people (see below). In addition, and in reality, damage control is also performed through fencing and other measures more directly related to protecting the crop. In the model this would have worked through $\gamma$. As we are neglecting such measures, $\gamma$ is assumed to be constant.

10. As noticed above, the survival rate is equal to $s=e^{-q a T}$. Hence, $C>0$ for all $T>0$.

11. A shadow price is therefore now imposed on the wildlife. It can easily be shown that it is positive only as long as $\left[P_{A} \gamma \beta-P_{H} q a\right]>0$ holds; that is, the non-nuisance case (see the main text below). Accordingly, the shadow price is zero in the no property rights case.

12. Harvesting is not strictly illegal in parts of the western side of the Serengeti National Park, and persons having a car and firearms can obtain a hunting licence (Rugumayo 1999).

\section{References}

Arcese, P., J. Hando and K. Campbell (1995), 'Historical and Present-Day Anti-Poaching Efforts in Serengeti', in A. R. E. Sinclair and P. Arcese, eds., Serengeti II (pp. 506-533). Chicago: University of Chicago Press.

Barrett, C.B. and P. Arcese (1998), 'Wildlife Harvest in Integrated Conservation and Development Projects', Land Economics, 74(4), 449-465.

Bromley, D. (1991), Environment and Economy. Oxford: Blackwell.

Bulte, E. and G. van Kooten (1999), 'The Ivory Trade Ban and Elephant Numbers: Theory and Application to Zambia', American Journal of Agricultural Economics 81(4), 453-466.

Campbell, K. and H. Hofer (1995), 'People and Wildlife: Spatial Dynamics and Zones of Interaction', in A. R. E. Sinclair and P. Arcese, eds., Serengeti II (pp. 534-570). Chicago: University of Chicago Press.

Clark, C. W. (1990), Mathematical Bioeconomics, 2nd ed. New York: Wiley.

Caughley, G. and A. Sinclair (1994), Wildlife Ecology and Management. Oxford: Oxford University Press.

Emerton, L. and I. Mfunda (1999), 'Making Wildlife Economically Viable for Communities Living around the Western Serengeti, Tanzania', Evaluating Eden Series Discussion Paper, No. 1. London: International Institute for Environment and Development.

Fancy, S., K. Whitten and D. Russel (1994), 'Demography of the Porcupine Caribou Herd', Canadian Journal of Zoology 72(5), 840-846.

Fryxell, J. M. (1995), 'Aggregation and Migration by Grazing Ungulates in Relation to Resources and Predators', in A. R. E. Sinclair and P. Arcese, eds., Serengeti II (pp. 257-273). Chicago: University of Chicago Press.

Getz, W. and R. Haight (1989), Population Harvesting. Princeton: Princeton University Press. 
Gordon, H. S. (1954), 'The Economic Theory of a Common Property Resource: The Fishery', The Journal of Political Economy 62, 124-142.

Holmern, T. et al. (2002), 'Uneconomical Game Cropping in a Community-based Conservation Project Outside the Serengeti National Park, Tanzania', Oryx 36(4), 364-372.

Homans, F. R. and J. E. Wilen (1997), 'A Model of Regulated Open Access Resource Use', Journal of Environmental Economics and Management 32(1), 1-21.

Kiss, A. (1990), 'Living with Wildlife: Wildlife Resource Management with Local Participation in Africa', Technical Paper 130. Washington, DC: World Bank.

Mangel, M. et al. (1996), 'Principles for the Conservation of Wild Living Resources', Ecological Application 6(2), 338-362.

Marks, S. A. (1984), The Imperial Lion: Human Dimensions of Wildlife Management in Africa. Boulder: Westview Press.

Munro, G. and A. Scott (1985), 'The Economics of Fishery Management', in A. Kneese and J. Sweeney, eds., Handbook of Natural Resource and Energy Economics, Vol. 2 (pp. 623-673). Amsterdam: Elsevier Science.

Murray, M. G. (1995), 'Specific Nutrient Requirements of Wildebeest', in A. R. E. Sinclair and P. Arcese. eds., Serengeti II (pp. 231-256). Chicago: University of Chicago Press.

Naughton-Treves, L. and S. Sanderson (1995), 'Property, Politics and Wildlife Conservation', World Development 23(8), 1265-1275.

Rugumayo, C. R. (1999), The Participation in Sustainable Resource Management. The Case of Serengeti Regional Conservation Strategy, Tanzania, Working Paper 112. Oslo: Norwegian Institute for Urban and Regional Research.

Sinclair, A. R. E. (1984), 'The Function of Distance Movements in Vertebrates', in I. R. Swingland and P. J. Greenwood, eds., The Ecology of Animal Movement. Oxford: Clarendon Press.

Sinclair, A. R. E. (1995), 'Serengeti Past and Present', in A. R. E. Sinclair and P. Arcese, eds., Serengeti II (pp. 3-30). Chicago: University of Chicago Press.

Sinclair, A. R. E. and P. Arcese (1995), 'Serengeti in the Context of Worldwide Conservation Efforts', in A. R. E. Sinclair and P. Arcese, eds., Serengeti II (pp. 31-46). Chicago: University of Chicago Press.

Skonhoft, A. (1998), 'Resource Utilisation, Property Rights and Welfare. Wildlife and the Local People', Ecological Economics 26(1), 67-80.

Skonhoft, A. and J. T. Solstad (1998), 'The Political Economy of Wildlife Exploitation', Land Economics 74(1), 16-31.

Smith, V. L. (1975), 'The Primitive Hunter Culture, Pleistocene Extinction, and the Rise of Agriculture', Journal of Political Economy 83(4), 727-755.

SRCP (1998), Overview of the Communities Surrounding the Ikorongo/Grumeti Game Reserves. Arusha, Tanzania: Report for the Ministry of Natural Resources and Tourism.

Swallow, S. (1990), 'Depletion of the Environmental Basis for Renewable Resources. The Economics of Interdependent Renewable and Non-renewable Resources', Journal of Environmental Economics and Management 19(3), 281-296.

Swanson, T. M. and E. B. Barbier (1992), Economics for the Wilds: Wildlife, Wildlands, Diversity and Development. London: Earthscan.

TANAPA (1996), Serengeti National Park. Management Zone Plan/Environmental Impact Assessment. Tanzania: Tanzanian National Parks.

Wright, R. (1999), 'Wildlife Management in the National Parks: Questions is Search of Answers', Ecological Applications 9, 30-36.

Zivin, J., B. M. Hueth and D. Zilberman (1998), 'Managing a Multiple-use Resource: The Case of Feral Pig Management in California Rangeland', Journal of Environmental Economics and Management 39(2), 189-204. 
Appendix 1. Comparative Static Results

The comparative static of the no property rights scenario is found by taking the total differential of (6) and (13). The result is

$$
\begin{aligned}
& {\left[\begin{array}{cc}
1 & -[1+r-2 / s] K q T / r s \\
P_{H} q T s+P_{A} \gamma \beta C / a & Q
\end{array}\right]\left[\begin{array}{c}
d X_{0} \\
d a
\end{array}\right]=} \\
& \quad\left[\begin{array}{c}
0 \\
-P_{A} \beta X_{0} C / a
\end{array}\right] d \gamma+\left[\begin{array}{c}
0 \\
-q X_{o} T s
\end{array}\right] d P_{H}+\left[\begin{array}{c}
0 \\
A^{\prime}(N) T-\gamma \beta X_{0} C / a
\end{array}\right] d P_{A} \\
& \quad+\left[\begin{array}{c}
q a K[1+r-2 / s] / r s \\
G
\end{array}\right] d T
\end{aligned}
$$

where $Q=-P_{H} X_{0}(q T)^{2} s+P_{A} A^{\prime \prime} T^{2}+P_{A} \gamma \beta X_{0} q T s / a<0$ from the second order maximum conditions while the sign of $G=P_{A} A^{\prime}(N)-P_{A} A^{\prime \prime}(N) a T-$ $s(1-q a T) X_{0}\left[P_{H} q a-P_{A} \gamma \beta\right] / a$ is ambiguous. The determinant of the system $Q+$ $K q T\left[P_{H} q T s+P_{A} \gamma \beta C / a\right][1+r-2 / s] / r s$ is also negative due to the second order conditions.

The comparative static results when having property rights are found when taking the total differentiation of (14) and (6). Equations (A2)-(A4) give the stock effects where $Z>$ 0 from the second order maximum condition.

$$
\begin{aligned}
& d X_{0} / d \gamma= \\
& \quad P_{A} \beta\left[X_{0} C-(1-s) T K[(r+1)-2 / s] / r s\right] q T K[(r+1)-2 / s] / Z r a s<0 \\
& d X_{0} / d P_{H}= \\
& \quad q T\left[X_{0} s+(1-s) K[(r+1)-2 / s] / r s\right] q T K[(r+1)-2 / s] / \text { Zras } \\
& d X_{0} / d P_{A}= \\
& \quad\left\{\begin{array}{l}
\gamma \beta X_{0} C-\gamma \beta T(1-s) T K[(r+1)-2 / s] / r s \\
-A^{\prime}(N) a T
\end{array}\right\} q T K[(r+1)-2 / s] / \text { Zras }
\end{aligned}
$$

\section{Appendix 2. The Numerical Analysis}

As mentioned in the main text, the ecological model is specified for the numerical analysis at the scale of one $\mathrm{km}^{2}$ and one year. The same scale is also used for the agricultural benefit, as well as the hunting benefit, given in 1998/99 prices. The protected area, consisting of Serengeti National Park and its surrounding game reserves, covers an area of some $26000 \mathrm{~km}^{2}$ (TANAPA Planning Unit 1996). The outer area is considered the catchment area surrounding the western edge of the protected area. Following Campbell and Hofer (1995), we assume that the catchment area, where the local people are originated, is located with a maximum distance of $45 \mathrm{~km}$ to the protected area. This area constitutes some $30500 \mathrm{~km}^{2}$ (Campbell and Hofer 1995). The human population in the outer area is estimated to be about 1.1 million with an average household size of about 7 persons (Campbell and Hofer 1995). Accordingly, there will be about 5 households per $\mathrm{km}^{2}$ in the outer area. On average, 2 persons per household work in agricultural production and hunting. Hence, the effort constraint $L$ yields $10 \times 365$ days a year, and we have $3650=N+a T$. 
Table AI. Baseline values prices and costs (1998/99-prices), ecological parameters and other parameters

\begin{tabular}{lll}
\hline Parameter & Description & Value \\
\hline$P_{H}$ & Meat price & $16(\$ /$ animal $)$ \\
$q$ & Catchability coefficient & $0.0008(1 / \mathrm{day})$ \\
$P_{A}$ & Crop price & $0.15(\$ / \mathrm{kg})$ \\
$\alpha$ & Input elasticity labour crop production & 0.8 \\
$\mu$ & Productivity crop production & $28(\mathrm{~kg} / \mathrm{day})$ \\
$\beta$ & Fraction daily consumption of dry forage & 0.03 \\
$\gamma$ & Fraction dry forage consumption crop & 0.12 \\
$L$ & Total available effort & $3650($ day $)$ \\
$T$ & Length of migration period & $122($ day $)$ \\
$K$ & Carrying capacity & $59($ animal $)$ \\
$r$ & Intrinsic growth rate & 0.3 \\
\hline
\end{tabular}

The wildebeest migration is related to rainfall and the wildebeest population enters agricultural land while it grazes the northern grassland during the dry season. The length of the dry season is about four months (Barrett and Arcese 1998). Four months, or 122 days, is also assumed to be the length of the migration period, and hence, $T=122$ days. The wildebeest population is estimated to be about 1.3 million animals and the annual offtake to some 120000 animals (Campbell and Hofer 1995). The wildlife density during the period of migration is therefore about 43 animals per $\mathrm{km}^{2}$, while the total offtake is 4 animals per $\mathrm{km}^{2}$. The number of hunters per household in the western Serengeti is assumed to be about 0.2 (Campbell and Hofer 1995). Consequently, it is one person involved in hunting at full time basis for every 5 households, and the baseline value of $a$ is accordingly 1 . By imposing these values for $a$ and $T$ into the survival rate together with $H / X_{0}$ as $4 / 43$, the catchability coefficient is calculated from equation (4). The result is $q=0.0008$. Following Barrett and Arcese (1998), the hunting value of a wildebeest is about US\$16, $P_{H}=16$. The natural growth function is specified as logistic. To calibrate the wildlife stock to its base level the carrying capacity $K$ is set to 59 animals per $\mathrm{km}^{2}$ outer area, meaning that the ecosystem can carry a stock of wildebeest just below 1.8 million animals. The maximum specific growth rate is fixed as $r=0.3$ (Caughley and Sinclar 1994).

The yield function is specified as $A(N)=\mu N^{\alpha}$ with $\mu$ as a productivity parameter and $\alpha$ as a scale parameter. The scale parameter is given as 0.8 (Barrett and Arcese 1998). According to a questionnaire among 300 households in Serengeti and Bunda Districts in June-September 2001 (Anne Borge Johannesen, work in progress), the average plot size per household is 7.4 acres, corresponding to a cultivated area of a fraction of 0.15 per $\mathrm{km}^{2}$ for the average 5 households. For the same districts, the average value of the yield is estimated to be about US\$19 000 per $\mathrm{km}^{2}$ cultivated land (Emerton and Mfunda 1999). At our scale of one $\mathrm{km}^{2}$, this represents a value of $19.000 \times 0.15=\mathrm{US} \$ 2850$ (or US $\$ 570$ per household). The main crops grown in the Western Serengeti are sorghum, cassava, maize, and cotton (SRCP 1998). Personal communication (SRCP 1999) indicates a per kg price of US\$ 0.18 for sorghum, US\$ 0.05 for cassava, US\$ 0.11 for maize, and US\$ 0.19 
for cotton. By weighting the crop prices by the relative magnitude of these crops, we arrive at the price per kilo agricultural output equals US\$ 0.15. $P_{A}=0.15$. Consequently, for the specified yield function we have $P_{A} \mu N^{\alpha}=0.15 \times \mu(3650-1 \times 122)^{0.8}=2850$, balancing with $\mu=28$.

The wildebeest has a daily consumption of about $3 \%$ of their body weight in dry forage (Murray 1995), hence, $\beta=0.03$. When assuming an average weight of $150 \mathrm{~kg}$ per animal, the daily consumption of dry forage is therefore $4.5 \mathrm{~kg}$ per animal. To obtain a value for the fraction of the forage eaten from the crops $\gamma$, we use the first order condition (13). For the above estimated parameter values together with the imposed values for $a$ and $X_{0}$, $\gamma=0.12$ balances this equation. Hence, through this calibrating we find that $12 \%$ of the wildebeests daily consumption of dry forage is from crops. Plugging into equation (8) this corresponds to a yearly damage on crop production of about $14 \%$. This is the average of the estimates found in Emerton and Mfunda (1999) and Anne Borge Johannesen (work in progress). Table AI summarises the baseline parameter values. 